\title{
BMJ Open Historical cancer incidence and mortality assessment in an Illinois community proximal to a former manufactured gas plant
}

\author{
Dominik D Alexander, Xiaohui Jiang, Lauren C Bylsma, David H Garabrant, \\ Sarah R Irvin, Jon P Fryzek
}

To cite: Alexander DD, Jiang X, Bylsma LC, et al. Historical cancer incidence and mortality assessment in an Illinois community proximal to a former manufactured gas plant. BMJ Open 2014;4:e006713. doi:10.1136/bmjopen-2014006713

- Prepublication history for this paper is available online. To view these files please visit the journal online (http://dx.doi.org/10.1136/ bmjopen-2014-006713).

Received 22 September 2014 Revised 4 December 2014 Accepted 5 December 2014

CrossMark

EpidStat Institute, Ann Arbor, Michigan, USA

Correspondence to

Dr Jon Fryzek;

jon@epidstat.com

\section{ABSTRACT}

Objectives: Concern has been raised that the occurrence of cancer may be increased in neighbourhoods around a former manufactured gas plant in Champaign, Illinois, USA. Thus, we compared historical rates of cancer in this area to comparison communities as well as with nationally standardised rates.

Design: Retrospective population-based community cancer assessment during 1990-2010.

Setting: Champaign County, Illinois, USA, and zip codes encompassing the location of the former manufactured gas plant to counties that were similar demographically.

Participants: Residents of the counties and zip codes studied between 1990 and 2010 .

Main outcome measures: The relative risk (RR) and $95 \% \mathrm{Cl}$ were used to compare cancer incidence and mortality in the areas near the gas compression site to the comparison counties. Standardised incidence ratios (SIRs) were calculated to compare rates in the areas near the gas compression site to expected rates based on overall US cancer rates.

Results: Total cancer mortality (RR $=0.91,95 \% \mathrm{Cl}$ 0.88 to 0.94 ) and incidence ( $R R=0.95,95 \% \mathrm{Cl} 0.94$ to 0.97 ) were reduced significantly in Champaign County versus the comparison counties. Similarly, a reduced rate of total cancer was observed in analyses by zip code (proximal to the former gas plant) when compared with either similar counties (RR $=0.89,95 \%$ $\mathrm{Cl} 0.86$ to 0.93 ) or national standardised rates of cancer (SIR=0.88, 95\% Cl 0.85 to 0.91 ).

Conclusions: This historical cancer assessment did not find an increased risk of total cancer or specific cancer types in communities near a former manufactured gas plant site.

\section{INTRODUCTION}

The production of manufactured gas is widely considered one of the key developments in our industrial history, with an extensive chronology beginning in the late 1700 s and

\section{Strengths and limitations of this study}

- The validity of our results is enhanced by the utilisation of three comparison populations: (1) counties very well matched demographically that had former gas plants, (2) comparison counties without former gas plants and (3) nationally representative cancer data from the Surveillance, Epidemiology, and End Results (SEER) programme.

- Because of the complete, systematic and statewide registry in Illinois, data for persons diagnosed with cancer were assembled in an unbiased fashion. Identification and reporting of cancer cases in the Illinois State Cancer Registry (ISCR) is mandated by state law.

- A priori, we developed a systematic protocol for identifying comparable counties. We matched counties based on residential status (urban/rural) and similar demographic and socioeconomic characteristics, and our analyses were adjusted for age, sex and race (at the county level) to control for confounding.

- Our cancer assessment is ecological in nature; thus, aside from age, sex and race, we could not model or adjust for factors associated with cancer such as physical activity, family history of disease or body mass index that may have influenced the results.

- The population sizes (ie, the denominator for estimating cancer rates) for the study periods were based on the 1990 and 2000 census information. If there was considerable in-migration or out-migration of the population over time, the estimated RRs may have been affected.

spanning into the 1960s. Manufactured gas consisted largely of the gasification of coal and, less frequently, the combustion of other materials such as wood and oil. Historically, the manufactured gas industry grew significantly in the early 1800 s due to the production of lighting for the progress and development of cities. However, later in the 19th century, this industry diversified into heating, refrigeration and cooking. During the early to 
mid-20th century, the advent of natural gas obviated the gasification of coal, ultimately leading to the conversion or closure of manufactured gas plants. Pipelines transported natural gas directly from the well to gas distribution systems, and natural gas was considered more economical, efficient and environmentally friendly. Most manufactured gas plants in the USA were terminated by 1966 with few exceptions, and as a result of the manufactured gas demise, over 1500 plant sites are suggested to remain dormant or vacant in the USA today.

Numerous health concerns have been raised regarding possible environmental exposures stemming from manufactured gas plant sites. Foremost among the concerns is that contamination and waste products from the manufacturing gas process leaked into the adjacent soil and groundwater, thus posing health risks in the nearby residential areas and communities. ${ }^{1}$ The process of coal carbonisation generates coal tar, which are complex mixtures of heterocyclic compounds, phenols and polycyclic aromatic hydrocarbons (PAHs). Indeed, both volatile organic compounds (VOCs) and semi-VOCs (SVOCs) from coal tar and petroleum products are derived from the coal gasification process. ${ }^{1}$ The VOCs contain a mixture of BTEX, or benzene, toluene, ethylbenzene and xylene isomers among other compounds, while the SVOCs consist of a mixture of compounds, such as benzo(a)pyrene, benzo(e) pyrene, naphthalene and 2-methyl naphthalene. In addition, principal component analyses have identified heavy metals at former manufactured gas plant sites. ${ }^{2}{ }^{3}$ As a result of these gas process by-products, the US Environmental Protection Agency (EPA) and other regulatory agencies have focused on assessing the potential for soil and groundwater contamination at former manufactured gas plant sites, as well as evaluating the potential for health risks among residents in nearby communities. The International Agency for Research on Cancer (IARC) lists many of the manufactured gas plant by-product compounds as known, probable or possible carcinogens for specific cancers, but the level and extent of community exposure to such compounds resulting from former manufactured gas plants is uncertain. Furthermore, sparse epidemiological evidence exists on the potential public health risks associated with residing near former manufactured gas plant sites.

Concern has been raised that the occurrence of cancer may be increased in neighbourhoods around a former manufactured gas plant on a 3.5 acre lot in northern Champaign, Illinois, USA. The plant, in operation from 1887 until 1953, manufactured gas by heating coal. Coal tar and other production wastes were suggested to remain on site until the closing of the plant. AmerenIP has registered this site with the Illinois EPA under their Site Remediation Program. However, the potential long-term health effects of residents in the nearby community are unknown. Therefore, we conducted a historical cancer incidence and mortality assessment using publicly available cancer data and census tract information to evaluate the occurrence of cancer in the community where the former manufactured gas plant was located compared with other communities with and without former gas plants that have similar demographic and lifestyle characteristics. In addition, we conducted standardised incidence analyses for Champaign County and the study zip codes using nationally representative cancer data.

\section{METHODS}

All data used in this study are publicly available. Specifically, the cancer incidence data were obtained from the Illinois Department of Public Health and from the Surveillance, Epidemiology, and End Results (SEER) programme, while cancer mortality data were obtained from SEER. Analyses for cancer incidence are presented at both the county and zip code level while analyses for cancer mortality are presented at the county level, which is the smallest area for which cancer mortality data are available. County and zip code demarcations were based on information provided by the US Census Bureau.

\section{Study areas}

The analytical and comparison population areas were characterised using census tract information. The former manufactured gas plant of interest was located in Champaign County, Illinois, USA, and was circumscribed by zip codes 61820 and 61801 ; thus, these demarcated areas served as the analytical group. Because our assessment was community-based and ecological in nature, our objective was to identify comparison counties in the state of Illinois with similar demographic and socioeconomic characteristics. Relevant characteristics included county setting (urban vs rural), county population size, and percentages for black race, high school graduation, persons over age 65 , persons unemployed, families below poverty level, urban residence and ever-smoking status. In addition, the median household income was utilised as a comparison factor. County selection was based on methods developed by the National Cancer Institute. ${ }^{4}$

\section{Illinois cancer data}

In concert with the Illinois State Cancer Registry (ISCR), the SEER programme of the National Cancer Institute is the source of data for cancer mortality between 1986 and $2010 .{ }^{6}$ These data are grouped by age, sex and race and are provided at the county level (the smallest available area for cancer mortality). The National Center for Health Statistics (NCHS) provides information on the underlying cause of death, coded to the International Classification of Diseases (ICD-9) ${ }^{7}$ for all deaths for years 1986 through 1998 and the ICD-10 for all deaths for year 1999 and later. ${ }^{8}$ Cancer mortality rates are available by single year for Illinois only, and deaths among nonresidents and deaths of unknown age or sex are omitted from the database calculations. Because of NCHS policy, rates are not calculated for stratified subgroups containing less than 10 deaths. For this analysis we used mortality 
data from 1990 to 2010 to be consistent with the census tract reporting periods.

Cancer incidence data for the direct community comparisons used in this study were collected by the ISCR and are available as a public use data set via the Illinois Department of Public Health for the years 1991-2010. All obtainable data are provided by the ISCR as a public service for the purpose of statistical reporting and analysis only. Case ascertainment is near complete as the identification and reporting of cancer cases is mandated by state law. Individual (personal) information has been de-identified, and the data have been aggregated into categories (eg, age, race, Hispanic ethnicity, year of diagnosis and type of cancer) within individual records. ${ }^{9}$ The number of cases reported in a particular region depends on the size of the geographic area in an effort to protect the privacy of individuals. The Illinois data set contains sanitised records of cancer incidence among residents who were diagnosed between 1986 and 2011. Cancer incidence data at the county and zip code level are based on 5-year interval groupings, and include data for invasive cancers only with the exception of bladder cancer. Non-melanoma skin cancers and reported cases with an unknown age or 'other' sex category are omitted by the ISCR. Cancer incidence data used for the standardised incidence ratio (SIR) analyses were obtained directly from the SEER programme.

By using these data, we agreed to comply with the Illinois Health and Hazardous Substances Registry Act (410 ILCS 525/12). All data used in our analyses are publically available; thus, informed consent was not required.

\section{Statistical analyses}

As indicated, we ascertained cancer rates from the ISCR and the SEER programme. The rates provided by these sources were calculated using the SEER*Stat software package, developed by the Information Management Services Inc for the National Cancer Institute. ${ }^{10}$ SEER expresses rates per 100000 population, and rates are age-adjusted by the direct method adjusting to the 2000 US standard million population. These data were then used to formulate the basis of our historical cancer assessment.

Because of the ecological nature of the communitybased analyses, we conducted analyses in an effort to account for potential confounding at the aggregate level while considering the potential for exposure misclassification. Thus, we conducted analyses using three different comparison populations based on: (1) Illinois counties that were the most closely matched demographically (irrespective of having former gas plants), (2) counties without former gas plants (as part of the selection criteria) that were relatively similar demographically and (3) nationally representative cancer data from the SEER programme. By utilising three different comparison populations, we were able to enhance the validity of our analyses, examine the consistency of cancer rates across different groups, and facilitate the identification of potential sources of statistical heterogeneity (if present). All types of analyses serve as complementary comparisons to appreciate fully any observed associations.

In the first type of analysis, we calculated relative rate ratios (RRs) and 95\% CIs to compare cancer mortality and incidence rates in Champaign County, Illinois, USA, and zip codes 61820 and 61801 encompassing the location of the former manufactured gas plant to counties that were the most similar demographically (ie, Macon, Winnebago and Sangamon counties). Although not part of the selection criteria, these counties had former gas plants but were the most demographically comparable based on our objective matching criteria. The number of cancer cases and deaths were ascertained for the period 1990 through 2010, and the absolute rate of cancer occurrence was calculated based on the county and zip code population size according to the US Census Bureau. The relative rate of cancer occurrence was calculated by dividing the rate of cancer in Champaign County and the zip codes (for cancer incidence only) by the rate of cancer in the comparison counties. County-level analyses were statistically adjusted for age, sex and race, and zip code-level analyses were adjusted for age and sex (race stratified data were not available at the zip code level, and mortality analyses were adjusted for age only).

Although the comparison counties in the first analyses were very well matched demographically to Champaign County, they had former gas plants, which raise concern about potential bias resulting from similar chemical exposures in the comparison counties. To address this concern, our second analyses consisted of comparing rates of cancer in Champaign County and the study zip codes with areas that did not have former gas plants but had relatively similar descriptive characteristics. To do this, we reviewed an EPA report on manufactured gas plant production, ${ }^{11}$ the EPA website, and the following website link: http://www.hatheway.net/state_site_pages/ il_epa.htm to identify additional comparison counties. Illinois counties with relatively similar demographic characteristics but without former gas plants (ie, Brown, Douglas, Menard, Randolph counties) were selected. Evaluations of cancer mortality and cancer incidence, using the same methodology as the first analyses, were conducted using these counties as comparisons.

In our final set of analyses, we calculated SIRs for cancer sites in Champaign County and the zip codes of interest. The numbers of observed cancers in Champaign County and in the study zip codes were compared with those expected on the basis of standardised rates of cancer in the general population using data obtained from SEER. ${ }^{12}$ The number of observed cancers was determined by sex, race and 5-year age groups (the zip codes were standardised by age and sex groups) for each year from 1991 to 2010. Expected numbers of cases were calculated by multiplying the estimated population for Champaign County and for the study zip codes for each year of study by annual SEER 
cancer rates, stratified by 5-year age groups, race and sex. Observed and expected counts were then generated for Champaign County and for the study zip codes, and SIRs were calculated by dividing the observed number by the expected number.

A final concern was the possibility of surveillance bias being introduced during the analytical study period. In the mid-2000s, a neighbourhood advocacy group formed to increase awareness about the potential health effects from the abandoned gas plant. ${ }^{13}$ In order to limit potential bias associated with the formation of this group, we conducted analyses for the years 1990-2000, prior to the formation of this group.

All analyses were performed using SAS statistical software.

\section{RESULTS}

\section{Study counties}

The characteristics of the study county and the comparison counties (with the most similar demographic characteristics) are reported in table 1 for the 1990 and 2000 census periods.

Champaign County was very well matched to the comparison counties with former gas plants on the variables of interest. Given the relatively high proportion of counties with former manufactured gas plants in Illinois, the availability of matching counties without former gas plants was more limited. However, based on our county scoring methodology and criteria, we were able to identify counties (ie, Brown, Douglas, Menard, Randolph) without former gas plants to serve as comparison communities in our second type of analyses. These counties were not as closely matched on potential confounding factors (ie, demographic characteristics) that may be associated with cancer as the counties used in the first analyses (table 2).

\section{Cancer mortality}

The RR for total cancer mortality in Champaign County versus the comparison counties most closely matched demographically (Macon, Winnebago and Sangamon) was significantly decreased ( $R R=0.91,95 \%$ CI 0.88 to 0.94 ) during 1990-2010 (table 3). Similarly, statistically significant deficits in mortality were observed for cancers of the oesophagus $(\mathrm{RR}=0.80,95 \%$ CI 0.65 to 0.98$)$, colorectum ( $\mathrm{RR}=0.88,95 \%$ CI 0.80 to 0.97$)$, pancreas $(\mathrm{RR}=0.78,95 \%$ CI 0.68 to 0.89$)$ and lung and bronchus ( $R R=0.85,95 \%$ CI 0.80 to 0.89 ). In fact, out of all 22 cancer site groupings, 17 RRs represented reduced risks, $1 \mathrm{RR}$ was 1.0, no data were available for one site (testicular cancer) and 3 RRs were slightly elevated. None of these elevated cancer sites was statistically significant, with RRs of 1.03 (melanoma), 1.06 (prostate) and 1.05 (leukaemias; table 3).

In our second set of analyses, similar results for Champaign County were observed when compared with counties without former manufactured gas plants. Total cancer was associated with an RR of 0.96 (95\% CI 0.92 to $1.00)$, and statistically significant reduced rates of colorectal (RR=0.85, 95\% CI 0.75 to 0.97$)$ and pancreatic cancer ( $\mathrm{RR}=0.81,95 \%$ CI 0.67 to 0.98 ) mortality were observed (data tables not shown, but available on request). Relative risks for most cancer sites were 1.0 or lower, with few weakly positive, albeit non-significant associations. No statistically significant associations for the more common cancers-lung and bronchus ( $\mathrm{RR}=0.94,95 \%$ CI 0.87 to 1.02 ), breast ( $\mathrm{RR}=1.00,95 \%$ CI 0.85 to 1.18 ) or prostate ( $\mathrm{RR}=1.00,95 \% \mathrm{CI} 0.84$ to 1.19$)$ were observed.

Taken together, results based on analyses using communities with and without former gas plants are not supportive of an increased risk of cancer mortality.

\section{Cancer incidence}

A statistically significant reduced rate of total cancer incidence was observed in Champaign County versus the comparison counties most closely matched demographically ( $R R=0.95,95 \%$ CI 0.94 to 0.97 ) during $1991-2010$ (table 4). Decreased incidence rates were observed for 19 of 23 cancer site groupings based on analyses during 1991-2010. Incidence rates for cancers of the colorectum, pancreas, lung and bronchus, testis, cervix, nervous system and 'other' sites (list of cancers in this category are shown in table 4) were all significantly lower versus the rates in the comparison counties. In contrast, statistically significant slightly elevated rates were observed for melanoma ( $\mathrm{RR}=1.12,95 \%$ CI 1.02 to 1.24$)$ and prostate cancer (RR=1.20, 95\% CI 1.14 to 1.25$)$. Restricting the analytical period to 1991-2000 in Champaign County in order to reduce potential bias associated with the formation of the neighbourhood advocacy group did not appreciably modify the results; the RR for melanoma was 1.17 (95\% CI 0.99 to 1.38 ) and the RR for prostate cancer was 1.17 (95\% CI 1.09 to 1.26 ; data not tabulated). Incidence rates were significantly reduced for total, colorectal, pancreatic, lung and bronchus, testicular, and cervical cancers during 1991-2000.

Fewer cancer subgroupings were available at the zip code level. Nevertheless, results similar to those in the county-level analyses were observed. Total cancer incidence was $11 \%$ lower in the study zip codes versus the most closely matched comparison counties, resulting in a statistically significant RR of 0.89 (95\% CI 0.86 to 0.93 ) during 1991-2010 (table 5). Of the 10 cancer site groupings, nine incidence rates were decreased versus comparison counties, including statistically significant reductions for colorectal ( $\mathrm{RR}=0.85,95 \%$ CI 0.76 to 0.95 ), breast (invasive; $\mathrm{RR}=0.86,95 \%$ CI 0.78 to 0.95 ) and 'other' ( $R R=0.86,95 \%$ CI 0.79 to 0.92$)$ cancers. The only elevated incidence rate was for prostate cancer, with a significant RR of 1.13 (95\% CI 1.03 to 1.24), based on 500 diagnosed cases during 1991-2010. However, no significant association was found for prostate cancer $(\mathrm{RR}=1.07$, 95\% CI 0.95 to 1.21) in the analysis for the period 19912000 (data not tabulated). During this period, rates for colorectal, breast and 'other' remained significantly decreased, while significant deficits for lung and bronchus ( $\mathrm{RR}=0.75,95 \%$ CI 0.66 to 0.86 ) and central nervous 


\begin{tabular}{|c|c|c|c|c|c|}
\hline \multirow[b]{2}{*}{ Characteristic } & \multirow{2}{*}{$\begin{array}{l}\text { Year of } \\
\text { census }\end{array}$} & \multirow[b]{2}{*}{ Champaign County } & \multicolumn{3}{|c|}{ Comparison counties most closely matched demographically } \\
\hline & & & Sangamon County & Macon County & Winnebago County \\
\hline \multirow[t]{2}{*}{ Rural-urban continuum code } & 1990 & $\begin{array}{l}\text { Counties in metropolitan } \\
\text { areas of }<250000\end{array}$ & $\begin{array}{l}\text { Counties in } \\
\text { metropolitan } \\
\text { areas of }<250000\end{array}$ & $\begin{array}{l}\text { Counties in } \\
\text { metropolitan } \\
\text { areas of }<250000\end{array}$ & $\begin{array}{l}\text { Counties in metropolitan } \\
\text { areas of 250 000-100 } 000\end{array}$ \\
\hline & 2000 & $\begin{array}{l}\text { Counties in metropolitan } \\
\text { areas of }<250000\end{array}$ & $\begin{array}{l}\text { Counties in } \\
\text { metropolitan } \\
\text { areas of }<250000\end{array}$ & $\begin{array}{l}\text { Counties in } \\
\text { metropolitan } \\
\text { areas of }<250000\end{array}$ & $\begin{array}{l}\text { Counties in metropolitan } \\
\text { areas of 250 000-100000 }\end{array}$ \\
\hline \multirow[t]{2}{*}{ Per cent black } & 1990 & 9.64 & 8.11 & 12.14 & 9.29 \\
\hline & 2000 & 11.82 & 10.17 & 14.76 & 11.16 \\
\hline \multirow{2}{*}{$\begin{array}{l}\text { Per cent did not graduate high } \\
\text { school }\end{array}$} & 1990 & 12.50 & 18.23 & 23.79 & 23.70 \\
\hline & 2000 & 9.02 & 11.93 & 16.83 & 18.57 \\
\hline \multirow[t]{2}{*}{ Per cent over age 65 years } & 1990 & 8.74 & 13.71 & 14.57 & 12.67 \\
\hline & 2000 & 9.72 & 13.51 & 15.24 & 12.73 \\
\hline \multirow[t]{2}{*}{ Per cent unemployed } & 1990 & 4.24 & 4.36 & 6.60 & 5.20 \\
\hline & 2000 & 5.52 & 4.07 & 7.15 & 5.83 \\
\hline \multirow[t]{2}{*}{ Per cent below poverty } & 1990 & 8.03 & 7.19 & 9.84 & 7.71 \\
\hline & 2000 & 6.92 & 6.49 & 9.28 & 6.92 \\
\hline \multirow[t]{2}{*}{ Median household income (in tens) } & 1990 & 2654 & 3035 & 2860 & 3134 \\
\hline & 2000 & 3778 & 4296 & 3786 & 4389 \\
\hline \multirow[t]{2}{*}{ Per cent urban } & 1990 & 81.41 & 78.32 & 81.74 & 87.41 \\
\hline & 2000 & 84.34 & 85.40 & 84.17 & 91.78 \\
\hline \multirow{2}{*}{ Per cent ever smoke } & 1990 & Not available & Not available & Not available & Not available \\
\hline & 2000 & 44.89 & 52.46 & 52.59 & 52.38 \\
\hline
\end{tabular}




\begin{tabular}{|c|c|c|c|c|c|c|}
\hline \multirow[b]{2}{*}{ Characteristic } & \multirow{2}{*}{$\begin{array}{l}\text { Year of } \\
\text { census }\end{array}$} & \multirow[b]{2}{*}{ Champaign County } & \multicolumn{4}{|c|}{ Comparison counties without former gas plants } \\
\hline & & & Brown & Douglas & Menard & Randolph \\
\hline \multirow[t]{2}{*}{ Rural-urban continuum code } & 1990 & $\begin{array}{l}\text { Counties in } \\
\text { metropolitan } \\
\text { areas of }<250000\end{array}$ & $\begin{array}{l}\text { Comp rural }<2500 \\
\text { urban population, not } \\
\text { adjacent to metro area }\end{array}$ & $\begin{array}{l}\text { Urban population of } \\
2500 \\
\text { to } 19999 \text {, adjacent to a } \\
\text { metro area }\end{array}$ & $\begin{array}{l}\text { Counties in } \\
\text { metropolitan } \\
\text { areas of }<250000\end{array}$ & $\begin{array}{l}\text { Urban population of } \\
2500 \\
\text { to } 19999 \text {, adjacent to a } \\
\text { metro area }\end{array}$ \\
\hline & 2000 & $\begin{array}{l}\text { Counties in } \\
\text { metropolitan } \\
\text { areas of }<250000\end{array}$ & $\begin{array}{l}\text { Urban population of } \\
2500 \\
\text { to } 19999, \text { not } \\
\text { adjacent to a metro } \\
\text { area }\end{array}$ & $\begin{array}{l}\text { Urban population of } \\
2500 \\
\text { to } 19999 \text {, adjacent to a } \\
\text { metro area }\end{array}$ & $\begin{array}{l}\text { Counties in } \\
\text { metropolitan } \\
\text { areas of }<250000\end{array}$ & $\begin{array}{l}\text { Urban population of } \\
2500 \\
\text { to } 19999 \text {, adjacent to a } \\
\text { metro area }\end{array}$ \\
\hline \multirow[t]{2}{*}{ Per cent black } & 1990 & 9.64 & 9.37 & 0.05 & 0.05 & 8.26 \\
\hline & 2000 & 11.82 & 18.29 & 0.43 & 0.46 & 9.56 \\
\hline \multirow{4}{*}{$\begin{array}{l}\text { Per cent did not graduate high } \\
\text { school } \\
\text { Per cent over age } 65 \text { years }\end{array}$} & 1990 & 12.50 & 31.14 & 25.97 & 22.69 & 35.78 \\
\hline & 2000 & 9.02 & 36.75 & 20.69 & 11.67 & 28.67 \\
\hline & 1990 & 8.74 & 16.83 & 15.26 & 15.06 & 15.33 \\
\hline & 2000 & 9.72 & 12.69 & 15.96 & 13.17 & 15.61 \\
\hline \multirow[t]{2}{*}{ Per cent unemployed } & 1990 & 4.24 & 6.03 & 4.4 & 4.35 & 6.46 \\
\hline & 2000 & 5.52 & 3.47 & 2.78 & 3.88 & 5.69 \\
\hline \multirow[t]{2}{*}{ Per cent below poverty } & 1990 & 8.03 & 10.47 & 6.92 & 7.13 & 8.75 \\
\hline & 2000 & 6.92 & 4.84 & 4.21 & 6.11 & 7.06 \\
\hline \multirow{4}{*}{$\begin{array}{l}\text { Median household income (in } \\
\text { tens) } \\
\text { Per cent urban }\end{array}$} & 1990 & 2654 & 2045 & 2676 & 2933 & 2586 \\
\hline & 2000 & 3778 & 3545 & 3944 & 4660 & 3701 \\
\hline & 1990 & 81.41 & 0.00 & 49.13 & 0.00 & 46.16 \\
\hline & 2000 & 84.34 & 58.66 & 36.69 & 24.66 & 57.3 \\
\hline \multirow{2}{*}{ Per cent ever smoke } & 1990 & Not available & Not available & Not available & Not available & Not available \\
\hline & 2000 & 44.89 & 49.76 & 48.98 & 50.81 & 55.14 \\
\hline
\end{tabular}

Table 2 Characteristics of study county and comparison counties without former gas plants on 1990 and 2000 census

Comparison counties without former gas plants

mp rural $<2500$

an population of

Counties in

Urban population of

metro area

2500

to 19999 , not metro area area

9.37

36.75

3.47

10.47

3545

49.76

48.98

50.81 
Table 3 Age adjusted mortality rates, RRs and 95\% Cl† in 1990-2010

\begin{tabular}{|c|c|c|c|c|c|c|c|c|}
\hline & \multicolumn{3}{|c|}{ Champaign County } & \multicolumn{3}{|c|}{$\begin{array}{l}\text { Comparison counties most closely } \\
\text { matched demographically }\end{array}$} & \multirow[b]{2}{*}{$\begin{array}{l}\text { Rate } \\
\text { ratio }\end{array}$} & \multirow[b]{2}{*}{$95 \% \mathrm{Cl}$} \\
\hline & $\begin{array}{l}\text { Number of } \\
\text { deaths }\end{array}$ & Rate & $95 \% \mathrm{Cl}$ & $\begin{array}{l}\text { Number of } \\
\text { deaths }\end{array}$ & Rate & $95 \% \mathrm{Cl}$ & & \\
\hline All cancer & 5611 & 187.2 & 182.3 to 192.2 & 27170 & 206.1 & 203.6 to 208.5 & $0.91^{*}$ & 0.88 to 0.94 \\
\hline $\begin{array}{l}\text { Oral cavity and } \\
\text { pharynx }\end{array}$ & 64 & 2.1 & 1.6 to 2.7 & 358 & 2.7 & 2.4 to 3.0 & 0.78 & 0.59 to 1.03 \\
\hline Oesophagus & 118 & 4.0 & 3.3 to 4.7 & 650 & 4.9 & 4.5 to 5.3 & $0.80^{*}$ & 0.65 to 0.98 \\
\hline Stomach & 94 & 3.1 & 2.5 to 3.8 & 494 & 3.7 & 3.4 to 4.1 & 0.84 & 0.67 to 1.05 \\
\hline Colorectal & 551 & 18.4 & 16.9 to 20.0 & 2765 & 20.8 & 20.1 to 21.6 & $0.88^{*}$ & 0.80 to 0.97 \\
\hline Liver & 87 & 2.9 & 2.3 to 3.6 & 420 & 3.2 & 2.9 to 3.5 & 0.91 & 0.71 to 1.15 \\
\hline Pancreas & 267 & 9.0 & 7.9 to 10.1 & 1526 & 11.5 & 11 to 12.1 & $0.78^{\star}$ & 0.68 to 0.89 \\
\hline $\begin{array}{l}\text { Lung and } \\
\text { bronchus }\end{array}$ & 1526 & 51.3 & 48.7 to 53.9 & 7990 & 60.6 & 59.2 to 61.9 & $0.85^{\star}$ & 0.80 to 0.89 \\
\hline Bone and joint & 12 & 0.3 & 0.2 to 0.6 & 43 & 0.3 & 0.2 to 0.4 & 0.94 & 0.42 to 1.89 \\
\hline Melanomas & 81 & 2.7 & 2.1 to 3.3 & 339 & 2.6 & 2.3 to 2.9 & 1.03 & 0.80 to 1.31 \\
\hline Breast $\ddagger$ & 438 & 25.6 & 23.3 to 28.2 & 2045 & 27.5 & 26.3 to 28.7 & 0.93 & 0.84 to 1.03 \\
\hline Prostate§ & 348 & 31.4 & 28.1 to 34.9 & 1427 & 29.7 & 28.1 to 31.3 & 1.06 & 0.94 to 1.19 \\
\hline Testis§ & - & - & - & - & - & - & - & - \\
\hline Cervix $\ddagger$ & 39 & 2.3 & 1.6 to 3.2 & 177 & 2.6 & 2.2 to 3.0 & 0.89 & 0.61 to 1.27 \\
\hline Uterine $\ddagger$ & 72 & 4.2 & 3.2 to 5.2 & 323 & 4.2 & 3.7 to 4.6 & 1.00 & 0.76 to 1.29 \\
\hline Ovarył & 159 & 9.3 & 7.9 to 10.8 & 716 & 9.5 & 8.8 to 10.2 & 0.98 & 0.82 to 1.17 \\
\hline $\begin{array}{l}\text { Kidney and renal } \\
\text { pelvis }\end{array}$ & 136 & 4.5 & 3.8 to 5.4 & 618 & 4.7 & 4.3 to 5.1 & 0.97 & 0.80 to 1.17 \\
\hline Bladder & 131 & 4.4 & 3.7 to 5.3 & 610 & 4.6 & 4.2 to 5.0 & 0.97 & 0.79 to 1.17 \\
\hline Nervous system & 119 & 3.8 & 3.2 to 4.6 & 596 & 4.6 & 4.2 to 5.0 & 0.83 & 0.68 to 1.02 \\
\hline $\begin{array}{l}\text { Hodgkin's } \\
\text { lymphomas }\end{array}$ & 13 & 0.4 & 0.2 to 0.7 & 61 & 0.5 & 0.4 to 0.6 & 0.88 & 0.44 to 1.61 \\
\hline $\mathrm{NHL}$ & 230 & 7.6 & 6.7 to 8.7 & 1096 & 8.3 & 7.8 to 8.8 & 0.92 & 0.79 to 1.06 \\
\hline Myelomas & 110 & 3.7 & 3.0 to 4.5 & 510 & 3.8 & 3.5 to 4.2 & 0.96 & 0.77 to 1.18 \\
\hline Leukaemias & 251 & 8.2 & 7.3 to 9.3 & 1029 & 7.8 & 7.4 to 8.3 & 1.05 & 0.91 to 1.21 \\
\hline
\end{tabular}

${ }^{*} p<0.05$.

†Tiwari et al ${ }^{13 a}$ modification for Cls.

†Female only.

§Male only.

NHL, non-Hodgkin's lymphomas.

system cancers ( $R R=0.55,95 \%$ CI 0.33 to 0.93 ) were observed as well.

Additional subgroup analyses for the cancer sites were conducted by individual zip codes and by analytical periods. The rate of prostate cancer during 1991-2010 was elevated with marginal significance for zip code $61820(\mathrm{RR}=1.15,95 \%$ CI 1.00 to 1.32 , based on 211 cases) but not for zip code $61801 \quad(\mathrm{RR}=1.12,95 \%$ CI 0.99 to 1.26 ; data not tabulated). No effect modification was apparent by zip code as the CIs for prostate cancer largely overlapped. No other statistically significantly cancer rates were observed during 1991-2010 but rates were modified in the inverse direction for colorectal (RR for zip code $61820=0.98,95 \%$ CI 0.84 to 1.15 ; zip code $61801=0.76,95 \%$ CI 0.65 to 0.88 ) and lung and bronchus (RR for zip code $61820=0.98$, $95 \%$ CI 0.86 to 1.13 ; zip code $61801=0.65,95 \%$ CI 0.57 to 0.75 ) cancers (data not tabulated). Interestingly, when analyses were conducted for the period 1991-2000, prostate cancer rates were modified by zip code (RR for zip code $61820=1.23$, $95 \%$ CI 1.02 to 1.48 ; zip code $61801=0.98$, $95 \%$ CI 0.83 to 1.16 ).
In the second type of analysis, counties without former manufactured gas plants were used as the comparison (data tables not shown, but available on request). No difference in total cancer was found between Champaign County and the comparison counties without former gas plants $(\mathrm{RR}=1.00,95 \% \mathrm{CI} 0.97$ to 1.02). Of 22 cancer site groupings, 12 had reduced rates in Champaign County, with statistically significant deficits for colorectal ( $\mathrm{RR}=0.83,95 \%$ CI 0.76 to 0.90$)$ and cervical cancer ( $\mathrm{RR}=0.66,95 \%$ CI 0.49 to 0.90$)$. Respiratory system cancers (lung and bronchus $\mathrm{RR}=0.95$ ), urinary tract cancers (kidney $\mathrm{RR}=0.99$; bladder $R R=1.01$ ) and lymphohaematopoietic malignancies (Hodgkin's lymphomas $\mathrm{RR}=0.89$; non-Hodgkin's lymphomas $\mathrm{RR}=0.96$; myelomas $\mathrm{RR}=0.99$; leukaemias $\mathrm{RR}=1.03$ ) were not elevated in Champaign County compared with the counties that did not have former gas plants. As with the first set of analyses, prostate cancer incidence was elevated slightly and significantly $(\mathrm{RR}=1.14,95 \%$ CI 1.06 to 1.23$)$ in Champaign County, but it was not significant in the study zip code analysis ( $\mathrm{RR}=1.09,95 \%$ CI 0.98 to 1.21$)$. The only other 
Table 4 Age, sex and race-adjusted incidence rate by county, RRs and $95 \% \mathrm{Cl}^{13 \mathrm{~b}}$ in $1991-2010$

\begin{tabular}{|c|c|c|c|c|c|c|c|c|}
\hline & \multicolumn{3}{|c|}{ Champaign County } & \multicolumn{3}{|c|}{$\begin{array}{l}\text { Comparison counties most closely } \\
\text { matched demographically }\end{array}$} & \multirow[b]{2}{*}{$\begin{array}{l}\text { Relative } \\
\text { rate }\end{array}$} & \multirow[b]{2}{*}{$95 \% \mathrm{Cl}$} \\
\hline & $\begin{array}{l}\text { Number of } \\
\text { cancers }\end{array}$ & Rate & $95 \% \mathrm{Cl}$ & $\begin{array}{l}\text { Number of } \\
\text { cancers }\end{array}$ & Rate & $95 \% \mathrm{Cl}$ & & \\
\hline All cancer & 13978 & 499.55 & 491.17 to 507.93 & 61184 & 524.18 & 520.03 to 528.34 & $0.95^{*}$ & 0.94 to 0.97 \\
\hline $\begin{array}{l}\text { Oral cavity and } \\
\text { pharynx }\end{array}$ & 332 & 11.94 & 10.64 to 13.23 & 1484 & 12.71 & 12.07 to 13.36 & 0.94 & 0.83 to 1.06 \\
\hline Oesophagus & 141 & 5.21 & 4.35 to 6.08 & 696 & 5.96 & 5.52 to 6.41 & 0.87 & 0.73 to 1.05 \\
\hline Stomach & 177 & 6.38 & 5.43 to 7.33 & 809 & 6.93 & 6.45 to 7.41 & 0.92 & 0.78 to 1.09 \\
\hline Colorectal & 1442 & 52.87 & 50.11 to 55.62 & 7140 & 61.17 & 59.75 to 62.59 & $0.86^{*}$ & 0.82 to 0.91 \\
\hline Liver & 112 & 3.94 & 3.20 to 4.67 & 486 & 4.16 & 3.79 to 4.53 & 0.95 & 0.77 to 1.16 \\
\hline Pancreas & 291 & 10.69 & 9.45 to 11.92 & 1558 & 13.35 & 12.69 to 14.01 & $0.80^{*}$ & 0.71 to 0.91 \\
\hline Lung and bronchus & 1945 & 71.76 & 68.55 to 74.96 & 10063 & 86.21 & 84.53 to 87.90 & $0.83^{*}$ & 0.79 to 0.87 \\
\hline Bone & 23 & 0.68 & 0.39 to 0.97 & 80 & 0.69 & 0.54 to 0.84 & 1.00 & 0.62 to 1.60 \\
\hline Melanomas & 539 & 17.62 & 16.10 to 19.14 & 1834 & 15.71 & 14.99 to 16.43 & $1.12^{*}$ & 1.02 to 1.24 \\
\hline Breast-invasive $†$ & 2184 & 150.65 & 144.25 to 157.04 & 9158 & 151.54 & 148.43 to 154.64 & 0.99 & 0.95 to 1.04 \\
\hline Prostate§‡ & 2254 & 172.52 & 165.38 to 179.66 & 8125 & 144.35 & 141.21 to 147.48 & $1.20^{*}$ & 1.14 to 1.25 \\
\hline Testis $\ddagger$ & 89 & 4.05 & 3.18 to 4.93 & 337 & 5.99 & 5.35 to 6.63 & $0.68^{*}$ & 0.53 to 0.86 \\
\hline Cervix† & 114 & 6.84 & 5.54 to 8.14 & 561 & 9.28 & 8.51 to 10.05 & $0.74^{*}$ & 0.60 to 0.91 \\
\hline Uterus† & 406 & 28.53 & 25.74 to 31.33 & 1801 & 29.80 & 28.42 to 31.18 & 0.96 & 0.86 to 1.07 \\
\hline Ovary† & 228 & 15.52 & 13.48 to 17.57 & 1022 & 16.91 & 15.87 to 17.95 & 0.92 & 0.79 to 1.06 \\
\hline Kidney & 425 & 15.10 & 13.64 to 16.55 & 1945 & 16.66 & 15.92 to 17.40 & 0.91 & 0.81 to 1.01 \\
\hline Bladder & 363 & 13.56 & 12.16 to 14.96 & 1725 & 14.78 & 14.08 to 15.48 & 0.92 & 0.82 to 1.03 \\
\hline Nervous system & 164 & 5.53 & 4.66 to 6.39 & 797 & 6.83 & 6.35 to 7.30 & $0.81^{*}$ & 0.68 to 0.96 \\
\hline \multicolumn{9}{|l|}{ Lymphomas } \\
\hline NHL & 556 & 19.64 & 17.98 to 21.29 & 2490 & 21.33 & 20.49 to 22.17 & 0.92 & 0.84 to 1.01 \\
\hline Myelomas & 183 & 6.68 & 5.71 to 7.66 & 758 & 6.49 & 6.03 to 6.96 & 1.03 & 0.88 to 1.21 \\
\hline Leukaemias & 433 & 15.32 & 13.86 to 16.79 & 1678 & 14.38 & 13.69 to 15.06 & 1.07 & 0.96 to 1.19 \\
\hline All other sites§ & 1484 & 50.63 & 48.00 to 53.26 & 6296 & 53.94 & 52.61 to 55.27 & $0.94^{*}$ & 0.89 to 0.99 \\
\hline \multicolumn{9}{|c|}{$\begin{array}{l}{ }^{*} \text { < }<0.05 . \\
\text { †Female only. } \\
\text { ¥Male only. } \\
\text { SIncludes small intestine, anus, intrahepatic bile duct, gallbladder, other biliary, retroperitoneum, peritoneum, other digestive organs, nose, } \\
\text { larynx, pleura, trachea, breast-invasive male only, soft tissue including heart, other non-epithelial skin, vagina, vulva, other female genital } \\
\text { organs, penis, other male genital organs, ureter, other urinary organs, eye, thyroid, other endocrine including thymus, mesothelioma, Kaposi } \\
\text { sarcoma and miscellaneous other sites. } \\
\text { NHL, non-Hodgkin's lymphomas. }\end{array}$} \\
\hline
\end{tabular}

statistically significant positive association in the county analysis was for oesophageal cancer $(\mathrm{RR}=1.46,95 \% \mathrm{CI}$ 1.07 to 1.99 ), but this finding was not substantiated in other analyses. Total cancer was significantly reduced in the study zip codes versus the comparison counties without former gas plants ( $\mathrm{RR}=0.94,95 \%$ CI 0.90 to $0.98)$. Moreover, 7 of 10 cancer sites were associated with reduced rates in the study zip codes, while 3 were slightly positive and not significant.

\section{SIR analyses}

During the period 1991-2010, 13978 total cancers were observed in Champaign County with 14150 expected based on nationally standardised rates, resulting in an SIR of 0.99 (95\% CI 0.97 to 1.00; data not tabulated). Of 23 cancer site groupings, 14 had expected or lower than expected cases of cancer, with statistically significant deficits observed for stomach, liver, pancreas, bone, melanoma, testicular, bladder, nervous system, Hodgkin's lymphoma and non-Hodgkin's lymphoma. A slightly greater than expected number of lung and bronchus ( $\mathrm{SIR}=1.07,95 \%$ CI 1.02 to 1.11 ) and kidney (SIR=1.13, $95 \%$ CI 1.03 to 1.25 ) cancer cases were observed in Champaign County, but these findings were not supported by the other analyses. In fact, a slight deficit of lung and bronchus cancer cases was observed in the study zip codes (SIR=0.98, 95\% CI 0.89 to 1.07 ), and urinary system cancer (includes kidney cancer) was reduced significantly ( $\mathrm{SIR}=0.78,95 \%$ CI 0.67 to 0.90 ) in the study zip codes (table 6). Significantly fewer than expected total cancer cases were observed in the study zip codes $(\mathrm{SIR}=0.88,95 \%$ CI 0.85 to 0.91 ; the SIRs for the cancer sites in the study zip codes are summarised in table 6).

\section{DISCUSSION}

We observed statistically significant reductions in total cancer mortality and incidence in Champaign County, 
Table 5 Age and sex-adjusted incidence rate by zip code, RRs and $95 \% \mathrm{Cl}^{13 \mathrm{~b}}$ in $1991-2010$

\begin{tabular}{|c|c|c|c|c|c|c|c|c|}
\hline & \multicolumn{3}{|c|}{ Zip 61820, 61801} & \multicolumn{3}{|c|}{$\begin{array}{l}\text { Comparison counties most closely } \\
\text { matched demographically }\end{array}$} & \multirow[b]{2}{*}{$\begin{array}{l}\text { Relative } \\
\text { rate }\end{array}$} & \multirow[b]{2}{*}{$95 \% \mathrm{Cl}$} \\
\hline & $\begin{array}{l}\text { Number of } \\
\text { cancers }\end{array}$ & Rate & $95 \% \mathrm{Cl}$ & $\begin{array}{l}\text { Number of } \\
\text { cancers }\end{array}$ & Rate & $95 \% \mathrm{Cl}$ & & \\
\hline All cancer & 3191 & 468.15 & 451.25 to 485.06 & 61184 & 524.18 & 520.03 to 528.34 & $0.89^{\star}$ & 0.86 to 0.93 \\
\hline $\begin{array}{l}\text { Oral cavity and } \\
\text { pharynx }\end{array}$ & 81 & 12.40 & 9.62 to 15.19 & 1484 & 12.71 & 12.07 to 13.36 & 0.98 & 0.77 to 1.23 \\
\hline Colorectal & 349 & 51.93 & 46.32 to 57.53 & 7140 & 61.17 & 59.75 to 62.59 & $0.85^{\star}$ & 0.76 to 0.95 \\
\hline Lung and bronchus & 440 & 67.81 & 61.34 to 74.27 & 10063 & 86.21 & 84.53 to 87.90 & 0.79 & 0.71 to 0.87 \\
\hline Breast-invasive† & 464 & 130.16 & 117.79 to 142.52 & 9158 & 151.54 & 148.43 to 154.64 & $0.86^{*}$ & 0.78 to 0.95 \\
\hline Cervix $†$ & 38 & 8.22 & 5.33 to 11.12 & 561 & 9.28 & 8.51 to 10.05 & 0.89 & 0.62 to 1.27 \\
\hline Prostate & 500 & 163.09 & 148.61 to 177.57 & 8125 & 144.35 & 141.21 to 147.48 & $1.13^{*}$ & 1.03 to 1.24 \\
\hline Urinary system & 186 & 28.87 & 24.61 to 33.13 & 3670 & 31.44 & 30.42 to 32.46 & 0.92 & 0.79 to 1.07 \\
\hline $\begin{array}{l}\text { Central nervous } \\
\text { system }\end{array}$ & 38 & 5.47 & 3.63 to 7.31 & 797 & 6.83 & 6.35 to 7.30 & 0.80 & 0.57 to 1.13 \\
\hline $\begin{array}{l}\text { Leukaemias and } \\
\text { lymphomas }\end{array}$ & 267 & 36.55 & 31.88 to 41.22 & 4509 & 38.63 & 37.50 to 39.76 & 0.95 & 0.83 to 1.08 \\
\hline All other cancers§ & 828 & 114.84 & 106.51 to 123.17 & 15677 & 134.31 & 132.21 to 136.41 & $0.86^{*}$ & 0.79 to 0.92 \\
\hline \multicolumn{9}{|l|}{$\begin{array}{l}{ }^{*} \mathrm{p}<0.05 \text {. } \\
\text { †Female only. } \\
\text { †Male only. }\end{array}$} \\
\hline
\end{tabular}

Illinois, USA, and the zip code study areas compared with counties that were similar demographically and socioeconomically, and based on nationally standardised

Table 6 Standardised incidence ratios (SIRs) and 95\% Cl of zip code 61820 and 61801, 1991-2010

\begin{tabular}{lrrll}
\hline Cancer sites & Obs & Exp & SIR & 95\% CI \\
\hline All cancer & 3191 & 3612 & 0.88 & 0.85 to 0.91 \\
Oral cavity and & 81 & 82 & 0.98 & 0.78 to 1.22 \\
pharynx & & & & \\
Colorectal & 349 & 378 & 0.92 & 0.83 to 1.03 \\
Lung and bronchus & 440 & 450 & 0.98 & 0.89 to 1.07 \\
Breast-invasive* $^{*}$ & 464 & 511 & 0.91 & 0.83 to 0.99 \\
Cervix* & 38 & 36 & 1.04 & 0.74 to 1.43 \\
Prostate† & 500 & 525 & 0.95 & 0.87 to 1.04 \\
Urinary system & 186 & 239 & 0.78 & 0.67 to 0.90 \\
Central nervous system & 38 & 63 & 0.60 & 0.43 to 0.83 \\
Leukaemias and & 267 & 320 & 0.84 & 0.74 to 0.94 \\
lymphomas & & & & \\
All other cancers $\ddagger$ & 828 & 1008 & 0.82 & 0.77 to 0.88 \\
\hline
\end{tabular}

${ }^{*}$ Female only.

†Male only.

łncludes oesophagus, stomach, liver, pancreas, bone,

melanomas, uterus, ovary, testis, myelomas, breast-invasive male only, small intestine, anus, intrahepatic bile duct, gallbladder, other biliary, retroperitoneum, peritoneum, other digestive organs, nose, larynx, pleura, trachea, soft tissue including heart, other non-epithelial skin, vagina, vulva, other female genital organs, penis, other male genital organs, ureter, other urinary organs, eye, thyroid, other endocrine including thymus, mesothelioma, Kaposi sarcoma and miscellaneous other sites.

Exp, expected; Obs, observed. rates. Furthermore, cancer occurrence was lower in the study area for most cancer types, with several statistically significant reductions in cancer rates. Results were largely consistent within and across analyses, with a few exceptions. Indeed, the lower mortality rates for most cancers in the study area versus the comparison counties were in accordance with the lower cancer incidence rates observed in Champaign County and the study zip codes. The only noteworthy positive associations in the primary analyses were for prostate cancer and melanoma. Neither prostate cancer mortality nor melanoma mortality was significantly elevated. However, incidence rates for these cancers were significantly increased in Champaign County. It is not clear why elevated rates were observed, although based on chance alone, it would be expected that some cancer rates would be statistically significant in the positive and inverse directions. As indicated, we observed several statistically significant inverse associations (ie, RRs below the null value of 1.0), such as for the lung and bronchus, colorectal and breast cancers. However, only two cancer types (prostate cancer and melanoma; incidence only) were associated with statistically significant positive associations. Thus, significant associations may have been observed due to multiple comparisons-a statistical phenomenon whereby 1 out of 20 associations is statistically significant due to chance. ${ }^{14}{ }^{15}$ In our analysis, we generated over 100 unique RRs.

Prostate cancer is the most common cancer among men in the USA, and 238590 incident cases and 29720 deaths were estimated to occur in $2013 .{ }^{16} 17$ The figures 
for prostate cancer represent $14.4 \%$ of all new cancer cases and $5.1 \%$ of all cancer deaths in the USA. ${ }^{17}$ Increasing age, African-American race, family history of prostate cancer, and genetic variations and mutations are established risk factors for prostate cancer, although the aetiology is largely unknown despite an extensive effort to identify causes of this malignancy. ${ }^{16}{ }^{17}$ The role of lifestyle and dietary factors are thought to play a role in prostate cancer risk, as past research has identified obesity, physical inactivity and smoking as significant modifiable risk factors for this malignancy. ${ }^{18-21}$ Our cancer assessment is ecological in nature; thus, aside from age, sex and race, we could not model or adjust for factors such as physical activity, family history of disease or body mass index that may have influenced the results. Based on a review of the literature and statements by prominent cancer organisations, ${ }^{16}{ }^{17}$ no manufactured gas plant by-product compound has been clearly or consistently associated with prostate cancer risk.

Perhaps the most likely reason for the elevation in prostate cancer incidence during 1991-2010 is the increased rate of prostate-specific antigen (PSA) screening in Champaign County versus the comparison counties. Indeed, based on the Behavioral Risk Factor Surveillance System (BRFSS) survey from the Centers for Disease Control and Prevention (CDC) and administered by the Illinois Department of Public Health, ${ }^{9}$ the per cent of men who underwent PSA screening was higher in Champaign County than Sangamon, Macon and Winnebago counties (as a composite percentage) during the study period. Furthermore, composite rates of PSA screening were higher in Champaign County than the counties without former gas plants. It is well established and well publicised that screening for prostate cancer results in an increase in incidence rates, whereas a proportion of prostate cancers may otherwise go undetected without screening. ${ }^{22-24}$ In a sentinel review paper on the epidemiological impact of screening on the incidence and mortality of prostate cancer in the USA, it was suggested that PSA testing was the likely cause of the dramatic increase in prostate cancer incidence during the 1990s. ${ }^{23}$ Although PSA testing is useful for early diagnosis, its value as a screening tool has been under scrutiny because the theoretical benefit on mortality is questionable. ${ }^{24}$ According to a recent study from the Prostate, Lung, Colorectal and Ovarian (PLCO) randomised screening trial, men who underwent annual prostate cancer screening with PSA testing and digital rectal examination had a $12 \%$ higher incidence rate of prostate cancer compared with men in the control group (who did not undergo PSA testing). ${ }^{25}$ However, approximately the same rate of death from prostate cancer was observed between groups, and no evidence of a mortality benefit was found in age or pretrial PSA testing strata. ${ }^{25}$ In our assessment, we observed a statistically significant increase in prostate cancer incidence in Champaign County (where a greater proportion of individuals underwent PSA testing) but no statistically significant difference in prostate cancer mortality versus the comparison counties.

Melanoma was also associated with a statistically significant positive association (incidence only). Cancer incidence data for melanoma were not available at the zip code level; thus, it is uncertain if melanoma occurrence was higher in the areas directly circumscribing the abandoned plant. Approximately 21.3 out of 100000 men and women are diagnosed annually with melanoma, and it is about 20 times more common in Caucasians than in African-Americans. ${ }^{17}$ The major risk factor for melanoma is exposure to ultraviolet (UV) rays (sunlight is the primary source of UV rays), particularly among persons with fair skin. Other risk factors include having a large number of moles, having one or more first-degree relatives who have had melanoma and being immunosuppressed. ${ }^{16}$ It has been hypothesised that malignant melanoma may occur as a result of exposure to occupational or environmental chemicals (eg, vinyl chloride, arsenic, polychlorinated biphenyls, petrochemicals, pesticides), particularly because malignancy can develop in cutaneous areas that have not been exposed to sunlight. ${ }^{26}$ However, the epidemiological evidence relating chemical exposures to melanoma risk is inconsistent. Thus, it is unclear whether the positive incidence rate ratio in Champaign County is the result of an artifactual finding from multiple comparisons, or has been confounded by sun exposure or other factors, such as immunosuppression. Moreover, general health concerns that the local population may have about living next to a former gas manufacturing site may lead to surveillance bias due to increased screening. Furthermore, a statistically significant deficit of melanoma was observed in Champaign County based on SIR analyses, and no statistically significant associations for melanoma were found based on comparisons with counties that did not have a former gas plant. Finally, oesophageal cancer incidence was elevated when Champaign County was compared with the non-gas plant counties in our sensitivity analysis of cancer incidence, but this observation was not substantiated by the main analyses, the sensitivity analysis of cancer mortality or by the SIR analysis.

Alternatively, an unknown manufactured gas product compound may have produced the slight elevations in prostate cancer and/or melanoma incidence in the main analyses. This scenario is unlikely, however, given the plausible explanations listed above and because reduced rates were observed for cancers with known environmental or chemical relationships. That is, no 'indicator' cancer types with established environmental or chemical aetiology were observed in excess. For example, IARC has classified 'coke production' as carcinogenic to humans (group 1) for lung cancer because of exposure to PAHs in the industry (although associations from the occupational studies are somewhat tenuous) ${ }^{27-29}$ In a quantitative review of occupational exposures to PAHs, lung cancer and bladder cancer risk was elevated significantly among workers in the coal 
gasification industry. ${ }^{30}$ However, in our assessment, we observed statistically significant reduced mortality and incidence rates of $15 \%$ and $17 \%$, respectively, for lung and bronchus cancers, and no associations for urinary system and bladder cancers. Moreover, our analyses were based on rates of cancer at the community level, not among workers likely exposed to much higher concentrations of possible chemical exposures.

It is unclear as to why there was a preponderance of inverse associations in Champaign County and the study zip codes versus the comparison counties. A priori, we developed a systematic protocol for identifying comparable counties. We identified counties based on residential status (urban/rural) and similar demographic and socioeconomic characteristics, and our analyses were adjusted for age, sex and race (at the county level). Based on the 2000 census information, there were approximately $7 \%$ fewer 'ever' smokers in Champaign County versus the comparison counties. This may explain, in part, the observation of lower cancer rates, particularly for lung and bronchus, in Champaign County. In addition, the prevalence of other potentially important factors, such as alcohol consumption or obesity, in these counties may have confounded the observed associations. However, relatively similar patterns of associations were observed in sensitivity analyses comparing Champaign County and the study zip codes with counties that did not have a former gas plant, and based on SIR analyses using nationally representative cancer data from the SEER programme.

Most of the literature on manufactured gas plants focuses on the environmental and ecological impacts of the gas process residues and waste products. As such, considerable literature exists on the methodological, toxicological, elemental chemistry and extracting techniques involving remediation and compound evaluations from abandoned sites. ${ }^{31-34}$ While potentially hazardous compounds may have been produced as part of the gas manufacturing process, the extent and level to which compound residues persist at the sites is unclear. In certain cases, potential hazards may be overestimated as samples in some studies have been consistent with background levels or below the assumed level. ${ }^{1}{ }^{35}$ As mentioned previously, the literature on direct or indirect human health risks from an epidemiological standpoint, is sparse. DeHate $e t a l^{1}$ investigated soil vapour intrusion at 10 commercial buildings and 26 single family and multifamily residential properties overlying and/or adjacent to three former manufactured gas plant sites. Soil vapour samples and indoor/outdoor air were analysed for VOCs, and comparative risks were evaluated based on maximum and mean concentrations for BTEX relative to background levels. All hazard indices were less than one or were comparable to mean and maximum background levels, and there was no evidence of manufactured gas plant-related soil vapour intrusion from any of the 36 sites. Based on these findings, the authors reported that no increased public health risks were associated with occupied residential or commercial properties overlying or surrounding former manufactured gas plant facilities. ${ }^{1}$ Occupational epidemiological studies involving postulated gas plant exposures, such as PAHs, ${ }^{2730}$ BTEX $^{36-38}$ and coal tar, ${ }^{30}{ }^{39-41}$ are extensive but none have evaluated potential disease outcomes resulting from residing in a community that includes a former manufactured gas plant site.

Our historical cancer assessment has limitations that are commonplace with analysing population-level data. Prime among the limitations is that we did not have individual-level information on lifestyle, dietary, medical or occupational factors. In addition, we did not have personal information regarding potential exposures (eg, to soil, groundwater or air) from the manufactured gas process. We were, however, able to adjust cancer estimates for age, sex and race. Because of the complete, systematic and statewide registry in Illinois, data for persons diagnosed with cancer were assembled in an unbiased fashion. Identification and reporting of cancer cases in the ISCR is mandated by state law. The population sizes (ie, the denominator for estimating cancer rates) for the study periods were based on the 1990 and 2000 census information. If there was considerable in-migration or out-migration of the population over time, the estimated RRs may have been affected. The gas plant ceased operations in 1953, and although immediate release of potential compounds may have diminished at that time, concern about the persistence of compounds over time in the vicinity has been raised. Our analyses were conducted on the basis of publically available aggregate-level data. We began our analytical period at the earliest time point possible that enabled us to merge cancer data and census data. Given our analytical periods, there is sufficient latency to observe a carcinogenic effect, if one exists. However, we were not able to capture cases that occurred in earlier time periods, with possible greater exposures. It may be possible that our analyses are not sensitive enough to identify small effects of plant exposures because of the nature of residential exposure classification. Despite these limitations, we found no clear or consistent evidence of an increase in cancer occurrence among residents in a community circumscribing a former manufactured gas plant.

The validity of our results is enhanced by the utilisation of three comparison populations: (1) counties very well matched demographically that had former gas plants, (2) comparison counties without former gas plants and (3) nationally representative cancer data from the SEER programme. These three types of analyses serve as complementary comparisons to examine the consistency of findings across different population metrics. We implemented an objective methodological approach to identify counties in the state of Illinois that were the most closely matched (demographically) to the analytical zones. By using this approach, we were able to account for some prominent confounding factors at the aggregate level. However, the most closely matched 
comparison areas also had former gas plants. Therefore, we conducted a second analysis by matching demographic factors that was restricted to counties without former gas plants. Finally, we conducted analyses using nationally standardised rates of cancer. Despite the variation in analytical approaches, results were consistent between techniques.

We conducted a community cancer assessment for the purpose of appraising the public health regarding the occurrence of cancer among residents in a community with a former manufactured gas plant. Although this study did not include individual-level information, rates of total cancer and most cancer sites in the Champaign County area and zip codes circumscribing the abandoned facility were lower versus similar comparison areas, and based on nationally standardised rates of cancer. The primary exception is for prostate cancer, although there may be relevant explanations for the higher rates aside from potential exposure emanating from the former manufactured gas plant site, such as an incidence spike due to higher PSA testing rates in Champaign County, a statistical artifact based on multiple comparisons, or confounding by unmeasured factors. Furthermore, a review of the literature did not reveal any known relation between the potential gas plant compounds and prostate cancer risk. Interpretation of results from our analyses should be made in the context of the many limitations of ecological-based study designs. However, the results from this retrospective cancer mortality and incidence assessment do not support an increase in cancer occurrence in communities surrounding a former manufactured gas plant in Champaign, Illinois, USA.

Contributors DDA, DHG and JPF were responsible for conception and design of the research. Statistical analyses were carried out by XJ. DDA, XJ, LCB, $\mathrm{DHG}, \mathrm{SRI}$ and JPF were responsible for development of the manuscript, critical revision and intellectual content.

Funding This work was supported by Ameren Corporation.

Competing interests DHG has served as an expert witness on behalf of Ameren in litigation related to manufactured gas plants. DDA, XJ, LCB, DHG, SRI and JPF are employed by EpidStat Institute, all of whom were contracted by Ameren Corporation to support the study.

Ethics approval Authors agreed to comply with the Illinois Health and Hazardous Substances Registry Act (410 ILCS 525/12). All data used in this study are publicly available; thus, informed consent was not required.

Provenance and peer review Not commissioned; externally peer reviewed.

Data sharing statement The full data set is available by emailing the corresponding author of the study.

Open Access This is an Open Access article distributed in accordance with the Creative Commons Attribution Non Commercial (CC BY-NC 4.0) license, which permits others to distribute, remix, adapt, build upon this work noncommercially, and license their derivative works on different terms, provided the original work is properly cited and the use is non-commercial. See: http:// creativecommons.org/licenses/by-nc/4.0/

\section{REFERENCES}

1. DeHate RB, Johnson GT, Harbison RD. Risk characterization of vapor intrusion in former manufactured gas plant sites. Regul Toxicol Pharmacol 2011;59:353-9.
2. Thavamani $P$, Megharaj $M$, Naidu R. Multivariate analysis of mixed contaminants (PAHs and heavy metals) at manufactured gas plant site soils. Environ Monit Assess 2012;184:3875-85.

3. Thavamani P, Megharaj M, Krishnamurti GS, et al. Finger printing of mixed contaminants from former manufactured gas plant (MGP) site soils: implications to bioremediation. Environ Int 2011;37:184-9.

4. Boice JD Jr, Bigbee WL, Mumma MT, et al. County mortality and cancer incidence in relation to living near two former nuclear materials processing facilities in Pennsylvania-an update. Health Phys 2009;96:128-37.

5. Boice JD Jr, Bigbee WL, Mumma MT, et al. Cancer incidence in municipalities near two former nuclear materials processing facilities in Pennsylvania-an update. Health Phys 2009;96:118-27.

6. National Cancer Institute DSRPCSB, Underlying mortality data provided by NCHS. Surveillance, Epidemiology, and End Results (SEER) Program (http://www.seer.cancer.gov) SEER ${ }^{\star}$ Stat Database: Mortality-All COD, Aggregated With County, Total U.S. (19692010) <Katrina/Rita Population Adjustment>-Linked to County Attributes-Total U.S., 1969-2011 Counties. 2014.

7. World Health Organization. Manual of the International Statistical Classification of Diseases, Injuries and Causes of Death, based on the recommendations of the Ninth Revision Conference, 1975. Geneva: World Health Organization, 1977.

8. World Health Organization. International Statistical Classification of Diseases and Related Health Problems. Geneva: World Health Organization, 1992

9. Ilinois State Cancer Registry, public dataset 1986-2011. Illinois Department of Public Health. 2014

10. Surveillance Research Program NCI. SEER ${ }^{\star}$ Stat software. 2013.

11. Harkins SM, Truesdale RS, Hill R, et al. U.S. production of manufactured gases: assessment of past disposal practices. Cincinnati, $\mathrm{OH}$ : Hazardous Waste Engineering Research Laboratory OoRaDUSE, 1988:1-410.

12. National Cancer Institute DSRPCSB. Surveillance, Epidemiology and End Results (SEER) Program-SEER ${ }^{*}$ Stat software. 2012

13. Champaign County Health Care Consumers. 5th \& Hill Toxic Site http://www.healthcareconsumers.org/index.php?action=Display\% 20Page\&id=562. 2014.

13a. Tiwari RC, Clegg LX, Zou Z. Efficient interval estimation for ageadjusted cancer rates. Stat Methods Med Res 2006;15:547-69.

13b. Breslow NE, Day NE. Statistical methods in cancer research. Volume II: the design and analysis of cohort studies. Lyon: International Agency for Research on Cancer, 1987:1-406.

14. Blair A, Stewart PA. Do quantitative exposure assessments improve risk estimates in occupational studies of cancer? Am J Ind Med 1992;21:53-63.

15. Steenland K, Bray I, Greenland S, et al. Empirical Bayes adjustments for multiple results in hypothesis-generating or surveillance studies. Cancer Epidemiol Biomarkers Prev 2000;9:895-903.

16. American Cancer Society. Cancer facts \& figures. Atlanta, GA: American Cancer Society, 2013.

17. National Cancer Institute. SEER stat fact sheets: prostate cancer: Surveillance, Epidemiology, and End Results Program. Bethesda, MD, 2013.

18. Morote J, Celma A, Planas J, et al. Sedentarism and overweight as risk factors for the detection of prostate cancer and its aggressivenes. Actas Urol Esp 2014;38:232-7.

19. Murphy AB, Akereyeni F, Nyame YA, et al. Smoking and prostate cancer in a multi-ethnic cohort. Prostate 2013;73:1518-28.

20. World Cancer Research Fund/American Institute for Cance Research. Food, nutrition, physical activity, and the prevention of cancer: a global perspective. Washington DC: AICR, 2007.

21. International Agency for Research on Cancer. Weight control and physical activity. In: Vainio H, Bianchini F. eds. IARC handbook of cancer prevention. Lyon, France: IARC Press, 2002:245-50.

22. Potosky AL, Miller BA, Albertsen PC, et al. The role of increasing detection in the rising incidence of prostate cancer. JAMA 1995;273:548-52.

23. Potosky AL, Feuer EJ, Levin DL. Impact of screening on incidence and mortality of prostate cancer in the United States. Epidemiol Rev 2001;23:181-6.

24. Chodak G. Prostate cancer: epidemiology, screening, and biomarkers. Rev Urol 2006;8(Suppl 2):S3-8.

25. Andriole GL, Crawford ED, Grubb RL III, et al. Prostate cancer screening in the randomized Prostate, Lung, Colorectal, and Ovarian Cancer Screening Trial: mortality results after 13 years of follow-up. J Natl Cancer Inst 2012;104:125-32.

26. Dika E, Fanti PA, Vaccari S, et al. Causal relationship between exposure to chemicals and malignant melanoma? A review and study proposal. Rev Environ Health 2010;25:255-9. 
27. Armstrong B, Hutchinson E, Unwin J, et al. Lung cancer risk after exposure to polycyclic aromatic hydrocarbons: a review and meta-analysis. Environ Health Perspect 2004;112:970-8.

28. Miller BG, Doust E, Cherrie JW, et al. Lung cancer mortality and exposure to polycyclic aromatic hydrocarbons in British coke oven workers. BMC Public Health 2013;13:962.

29. Baan R, Grosse Y, Straif K, et al. A review of human carcinogenspart F: chemical agents and related occupations. Lancet Oncol 2009;10:1143-4.

30. Bosetti C, Boffetta P, La VC. Occupational exposures to polycyclic aromatic hydrocarbons, and respiratory and urinary tract cancers: a quantitative review to 2005. Ann Oncol 2007:18:431-46.

31. Birak PS, Newman AP, Richardson SD, et al. Cosolvent flushing for the remediation of PAHs from former manufactured gas plants. $J$ Contam Hydrol 2011;126:72-84.

32. Richardson SD, Aitken MD. Desorption and bioavailability of polycyclic aromatic hydrocarbons in contaminated soil subjected to long-term in situ biostimulation. Environ Toxicol Chem 2011;30:2674-81.

33. Brown DG, Gupta L, Kim TH, et al. Comparative assessment of coal tars obtained from 10 former manufactured gas plant sites in the eastern United States. Chemosphere 2006;65:1562-9.
34. Vyas VM, Gochfeld MG, Georgopoulos PG, et al. An evaluation of the role of risk-based decision-making in a former manufactured gas plant site remediation. J Air Waste Manag Assoc 2006;56:225-35.

35. Stroo HF, Roy TA, Liban CB, et al. Dermal bioavailability of benzo[a] pyrene on lampblack: implications for risk assessment. Environ Toxicol Chem 2005;24:1568-72.

36. Durmusoglu E, Taspinar F, Karademir A. Health risk assessment of BTEX emissions in the landfill environment. $J$ Hazard Mater 2010;176:870-7.

37. Alexander DD, Wagner ME. Benzene exposure and non-Hodgkin Iymphoma: a meta-analysis of epidemiologic studies. J Occup Environ Med 2010;52:169-89.

38. Lerner JE, Kohajda T, Aguilar ME, et al. Improvement of health risk factors after reduction of VOC concentrations in industrial and urban areas. Environ Sci Pollut Res Int 2014;21:9676-88.

39. Boffetta P. Epidemiology of environmental and occupational cancer. Oncogene 2004;23:6392-403.

40. Swaen GM, Slangen JM. Mortality in a group of tar distillery workers and roofers. Int Arch Occup Environ Health 1997;70:133-7.

41. Roelofzen JH, Aben KK, Van de Kerkhof PC, et al. Dermatological exposure to coal tar and bladder cancer risk: A case-control study. Urol Oncol 2014. doi:10.1016/j.urolonc.2013.12.006 